\begin{tabular}{|c|c|c|}
\hline $\begin{array}{l}\text { ÇÜTAD } \\
\text { Çukurova Üniversitesi } \\
\text { Türkoloji Araștırmaları Dergisi }\end{array}$ & & $\begin{array}{l}\text { Cilt 6, Sayı } 2 \\
\text { Aralık } 2021\end{array}$ \\
\hline $\begin{array}{l}\text { ISSN: 2587-1900 } \\
\text { E-ISSN: 2548-0979 }\end{array}$ & $\begin{array}{l}\text { Geliş Tarihi: } \\
\text { Kabul Tarihi: }\end{array}$ & $\begin{array}{l}13.07 .2021 \\
20.11 .2021\end{array}$ \\
\hline \multicolumn{3}{|c|}{$\begin{array}{l}\text { Makale Künyesi (Çeviri): Gezer, Ş. (Çev.) (2021). Kabarlar ve Kara } \\
\text { Macarlar. Cukurova Üniversitesi Türkoloji Araştırmaları Dergisi, 6(2), } \\
\text { 1032-1041. }\end{array}$} \\
\hline \multicolumn{3}{|c|}{ https://doi.org/10.32321/cutad.970634 } \\
\hline
\end{tabular}

\title{
KABARLAR VE KARA MACARLAR ${ }^{1}$
}

\begin{abstract}
Sándor László TÓTH
ÖZET Çeviren: Şeyma GEZER ${ }^{2}$

881'den önce Hazar Kağanlığına isyan eden bazı Hazar grupları Macar boy birliğine katılmıştır. Ortak bir ad (Kabar) altında birleşerek bir boy beyi ile birlikte Macarların arasında yer almışlardır. Kaynaklarda (Ademarus Cabbanensis ve Querfurtlu Bruno) 11. yüzyılın ilk yıllarında ortaya çıkan Kara Macarlar ise bazı araştırmacılar tarafından Kabarlar ile ilişkilendirilmiştir, fakat bunlar Kral István'a ve Hıristiyanlığa karşı idi. Kronolojik sebeplerden ötürü Ajtony ve onun halkı Kara Macarlar olarak değerlendirilemez, aynı şekilde Kral István ile akrabalığı ve ittifak ilişkileri nedeniyle Aba Samuel' in yönetimi altındaki Kabarlar da Kara Macarlar olarak kabul edilemez. Buna karşın Koppány'nin ve Gyula'nın ulusu ise I. István'a karşı isyan ettikleri için Kara Macarlar olarak değerlendirilebilir.
\end{abstract}

Anahtar kelimeler: Kabarlar, Pagan Macarlar, Kara Macarlar, Hazar Kağanlığı.

\section{KABARS AND THE BLACK HUNGARIANS}

\section{ABSTRACT}

Before 881, some Khazar groups that rebelled against the Khazar Khaganate joined the Hungarian tribe union. They united under a common name (Kabar) and took their place among the Hungarians together with a tribe chief. The Black Hungarians, who appeared in the sources (Ademarus Cabbanensis and Bruno of Querfurt) in the early years of the 11th century, were associated with the Kabars by some researchers, but they were against King István and Christianity.

\footnotetext{
1 Makalenin orijinal ad1 ve künyesi: "Kabárok és fekete magyarok", Acta Historica, Tomus LXXXIV, Szeged, 1987, s. 23 - 29, University of Szeged, Department of Medieval and Early Modern Hungarian History, Dr., toths@hist.u-szeged.hu

${ }^{2}$ Ankara Üniversitesi, Sosyal Bilimler Enstitüsü, Batı Dilleri ve Edebiyatları Anabilim Dalı, Hungaroloji Bilim Dalı, Yüksek Lisans Öğrencisi. symgzr123@gmail.com

https://orcid.org/0000-0003-3959-6991
} 
For chronological reasons, Ajtony and his people cannot be considered Black Hungarians, just as the Kabars under Aba Samuel cannot be considered Black Hungarians due to their kinship and alliance with King István. On the other hand, Koppány's and Gyula's nation can be considered Black Hungarians as they rebelled against I. István.

Keywords: Kabars, Pagan Hungarians, Black Hungarians, Khazar Khanate.

Yedi Macar boyuna Etelköz'de katılan, fakat Karpat Havzası'ndaki yeni yurtlarında da onlarla birlikte yaşayan Kabarlar (Kavarlar) hakkında iki kaynak bilgi vermektedir. Annales Iuvavenses Maximi, 881 yılında şu bilgiyi muhafaza etmiş̧ir: "İlk savaş Macarlar ile Viyana'da. İkinci savaş Kabarlar ile Culmite'de."33 Bizans imparatoru Konstantinos Porphyrogenitus, De Administrando Imperio adıyla bilinen eserini 950 civarında tamamlamıştır, bunun 39 . bölümünün tamamı (ve 40. bölümün başındaki kısa iki kısım) Kabarların tarihinden bahseder. Buna göre "Kabarlar denilen kavim Hazarların soyundandır. Şöyle oldu, aralarında hükümete karşı bir isyan çıktı, iç savaş patlak verince önceki hükümetleri üstün geldi ve aralarından bazıları katledildi, diğerleri ise kaçtı. Türklerle birlikte Peçeneklerin yurduna giderek yerleştiler, birbirleriyle dostluk kurdular ve onlara bir çeşit Kabarlar adı verildi..."

Kabarların isyandan önce Hazarlardan sayıldıkları, yani Kağanlığın içerisinde muhtemelen etnik açıdan farklı olmadıkları bu Bizans malumatından açık bir şekilde görülüyor ${ }^{5}$. Müstakil Hazar Kabar etnik grubu, ancak iç savaştan sağ kurtulan isyancıların kağanlık topraklarını terk ettiklerinde ve Macar boyları ile yeni bir ortak yurda göç ettiklerinde teşekkül etmiştir. Konstantinos, Hazarlardan ayrılan kavim grupları ile bağlantılı olarak "birbirleriyle

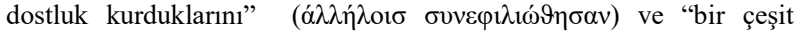

\footnotetext{
3 "Primum bellum cum Ungaris ad Weniam. Secundum bellum cum Cowaris ad Culmite.” Bkz. Monumenta Germaniae Historica, Scriptores I - XXXII, Hannoverae - Lipsiae 1826 - 1934, XXX/2, s. 762.

4 Bíborbanszületett Konstantin, A birodalom kormányzása. Yunanca metni yayımlayan ve Macarcaya çeviren Moravcsik Gy., Budapest (sonrakilerde: Bp.), 1950 (sonrakilerde DAI), s. 174 - 175; En yenisi için bkz. Moravcsik Gy., Az Árpád-kori magyar történet bizánci forrásai, Bp., 1984 (sonrakilerde Moravcsik, 1984), s. 46.

${ }^{5} \mathrm{Krş.} \mathrm{bir} \mathrm{önceki} \mathrm{dipnot,} \mathrm{yine} \mathrm{bkz.} \mathrm{Németh} \mathrm{Gy.,} \mathrm{A} \mathrm{honfoglaló} \mathrm{magyarság}$ kialakulása, Bp., 1930 (sonrakilerde Németh, 1930.), s. 234, 238; Kristó Gy., Levedi törzsszövetségétől Szent István államáig, Bp., 1980 (sonrakilerde Kristó, 1980), s. 114; Golden, P. B., Khazar Studies, An Historico-Philological Inguiry into the Origins of the Khazars, I, Bp., 1980 (sonrakilerde Golden, 1980), s. 135.
} 


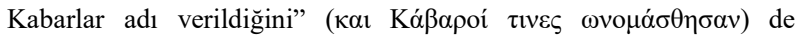
zikreder $^{6}$. Yani Kağanlıktan ayrılan Hazar grupları Etelköz'de birbirleriyle sıkı bir ilişkiye girmişlerdi, onlara ortak bir adla Kabar denilmesi de bunu gösteriyor. $\mathrm{Ne}$ bu adın etimolojisi, ne de bu adlandırmanın kimlerden geldiği tatmin edici bir şekilde aydınlatılmıştır. Geleneksel teoriye karşılık - ki buna göre Hazar Kağanlığı "başkaldıran" adını kendinden ayrılanlara koyardı - bu adın Macarlardan ya da daha ziyade bizzat Kabarların kendilerinden gelme ihtimalini göz ardı edemeyiz ${ }^{7}$. Son olasılığa bakılırsa, Hazar Kağanlığı'ndan ayrılan gruplar, önceki Hazar adının yerine Kabar (Kavar) adını bağımsızlıklarının, aidiyetlerinin bir işareti olarak almış olmalıydılar. Bunu Macarlar da benimsemişti, daha doğrusu kullanmışlardı, çünkü kendileriyle birlikte yaşayan Hazarlar ile Hazar Kağanlığı'nın halkını bu şekilde ayırmış olmalıydılar. Annales Iuvavenses Maximi'ye dayanarak, 881'de Macarların yanında batıda artık onlar da akınlara giriştikleri için, Hazar - Kabarların birleşmesinin 881'den önce gerçekleştiğini haklı olarak varsayabiliriz $^{8}$. Yıllık, Kabarları Macarlardan bağımsız bir boy olarak gösteriyor. Fakat Konstantinos, "sekiz boy arasından savaşlarda en güçlüleri ve en cesurları olarak gözüktükleri ve savaşta önde yürüdükleri için onları ilk boylar mertebesine yükselttiklerini” de kaydeder. ${ }^{9}$ Kabarların Macar boy birliğine bağlandıkları, onların savaşlarına katıldıkları bu Bizans malumatından anlaşılıyor. Her ne

${ }^{6}$ Keza metne istinaden Türklerin (Macarlar) ve Kabarların ya da Kabar gruplarının birbirleriyle dostluk kurması üzerine düşünülebilir. Dilbilimsel incelemelere dayanarak biz daha ziyade sonucu olasılığı düşünüyoruz. 39. bölümün ikinci cümlesinin ikinci yarısında öznenin yerini "bazıları...diğerleri" anlamındaki sözcükler (oí...oó) tamamlıyor, bunlar ilk cümlede geçen Kabarlara

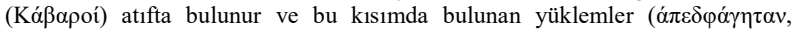

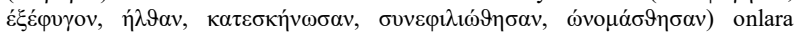
bağlidir.

7 "İsyan eden, baş kaldıran" etimolojisi için bkz. Vámbéry Á., A magyarok eredete, Bp., 1882, s. 69; Németh, 1930, s. 236 - 237; Golden, 1980, s. 136; Kristó, 1980, s. 114 - 115; Tolstov, Kabar adını Harezmli bir kavmin adına (Káliz) bağlar. Tolstov, Sz. P., Az ösi Khorezm, Bp, 1949, s. 232 - 233; Schönebaum, H., Zur Kabarenfrage. Aus der byzantinische Arbeit des Deutschen Demokratischen Republik I, Berlin, 1957, s. 143 - 145.

${ }^{8}$ Birleşme dönemine ilişkin görüşler için bkz. Tóth S., "Kabarok (kavarok) a 9. századi magyar törzsszövetségben”, Századok, 1984 (sonrakilerde Tóth, 1984), s. 102; 860'lı yıllara ilişkin en yeni görüş için bkz. Györffy Gy., "A kabar kérdés”, Forrás (7), 1983, s. 22.

${ }^{9}$ DAI, s. 174 - 175; Moravcsik, 1984, s. 46. 
kadar Macarlar ile Viyana'da, Kabarlar ile Culmite'de mücadele etseler de, ${ }^{10} 881$ 'deki olay da böyle ortak bir akın olmalıydı.

Kabarların teşkilatı kendilerine özgü bir biçimde oluşmuştu. Kağanlıktan ayrılıp yeni bölgeye yerleşmelerinin ardından müstakil bir boy birliği yahut kavim haline dönüşme olanağı teorik olarak vard1. İmparator Konstantinos, yedi boydan oluşan Türklere (Macarlara) benzer olarak, bağımsız bir bölümde Kabarlar üzerinde durur, bir yerde onları Türklerle uzlaşı halindeki bir kavim ( $\dot{\vartheta} v o v \varsigma$ ) olarak adlandırır ve onların üç boyunu ( anlatılanlara rağmen, yine de onlardan tek başına, bağımsız boy birliği oluşumu olarak bahsedemeyiz. Bunun iki sebebi vardır. Birincisi, Hazar Kağanlığı'ndaki iç savaşta isyan eden Hazarlar yenilgiler almışlardır, bu yüzden kaçanların nüfusu, tek başına yeni bir boy birliği kurmak için yeterli değildi. Bundan daha önemli olan ikinci sebep, Kabarların kendilerinden daha güçlü ve daha büyük bir kavmin yanına yerleşmiş olmasıdır. Yedi Macar boyu, bu yabancı kavmi boylardan oluşan bir boy birliği olarak değil, küçük bakiyelerden oluşan bir boy olarak kendisine bağlamış ve onları kendisine entegre etmiştir. Konstantinos’a göre Kabarlar, ortak askerî faaliyetler vesilesi ile görülen kahramanlıklarının ödülü olarak ilk boylar ( $\pi \rho \omega ́ \tau \alpha \iota ~ \gamma \varepsilon v \varepsilon \alpha i ́)$ haline getirilmişlerdi ve 40 . bölümün boy adları listesinde de birinci boy olarak $(\pi \rho \omega ́ \tau \eta . . \gamma \varepsilon v \varepsilon \alpha ́)$ geçerler. ${ }^{12} \mathrm{Bu}$, Kabarların diğer boyu geride bırakarak muharebeye başladıkları, yani öncü birlik statülerini

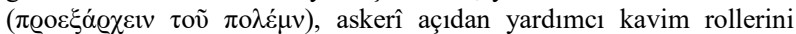
korudukları anlamına gelir. ${ }^{13}$ Bizans imparatoru şunu da kaydetmiştir: "Onlarda, yani bugün bile mevcut olan Kabarların üç boyunda, bir hükümdar ( $\tilde{\alpha} \varrho \omega v)$ vardır." ${ }^{14}$ Keza bu da Kabarlar kavminin boy birliğinden ziyade bir boy olarak hareket ettiğine tanıklık eder. $\mathrm{Bu}$ bazı Kabar gruplarının (üç "boyun”) adını bilmiyoruz, yalnızca ortak

\footnotetext{
${ }^{10}$ Culmite yer adının özdeşliği için (Kollmitz ya da Kulmberg) bkz. Kristó, 1980, s. 149; Macarlar ve Kabarlar ile yapılan muharebenin mekânı ve zamanı (yıllık, ilk önce 28 Ağustos'ta gerçekleşen bir güneş tutulmasını zikreder) için bkz. Vajay Sz. Der Eintritt des ungarischen Stämmebundes in die europäische Geschichte (862 - 933), Mainz, 1968 (sonrakilerde Vajay, 1968), s. 15, 23. dipnot.

${ }^{11}$ DAI, s. 174 - 175; Moravcsik, 1984, s. 46.

12 Kabar teşkilatının çelişkileri için bkz. Németh, 1930, s. 19; Constantine Porphyrogenitus, De Administrando Imperio, vol. II, Commentary, Ed. by Jenkins, R. J. H., University of London (sonrakilerde Commentary), s. 150; Tóth, 1984, s. 107.

${ }^{13}$ Bkz. Németh, 1930, s. 19, 234; Vajay, 1968, s. 16 - 17; Kristó, 1980, s. 65, 115, 118, 454.

${ }^{14}$ DAI, s. 174 - 175; Moravcsik, 1984, s. 46.
} 
kavmin ya da boyun adını biliyoruz; kendi liderleri yoktu, yalnızca ortak hükümdarları (boy beyleri) vardı.

Kabarların teşkilatı ile bağlantılı benzerliği, analojiyi Kangarlarda, Kürtgyarmat ve Uzlarda bulunan Peçenek boyu durumunda görebiliriz. İlki, üç Peçenek boyunun ortak adı (Kangar) idi, fakat her biri kendi adına ve kendi hükümdarına da sahipti. ${ }^{15}$ Macar Kürtgyarmat boyunun adı, iki boyun birleștirilmesinden (birbirine karıştığından) meydana geldiğini ifade eder, fakat bunların sadece bir lideri vardı ${ }^{16}$. Uzların 9. yüzyılın sonundaki saldırısından sonra, Peçeneklerin bir kısmı eski yurtlarında kalarak bu fatihlerle birlikte yaşamışlardır ve Peçenek adı altında Uz boy birliğinin bir parçası haline gelmişlerdir ${ }^{17}$. Burada kalan Peçenek boy bakiyelerinin tek bir boy olarak geçen rolü, Hazar Kağanlığı'ndan ayrılan Hazar gruplarının teşkilatı ile muhtemelen en yakın benzerlik anlamına gelir. Fark yalnızca, bu sonuncuların Macar boy birliğinde aslen Hazar olarak değil, Kabar adı altında yer almalarıdır. Konstantinos'a dayanarak, Kabar ve Macar boylarının teşkilat bağlantısını 1(3)+7 formülü ile ifade edebiliriz ${ }^{18}$.

Ortak yurttaki birliktelik, savaşlardaki birlik mücadelesinin sonucu olarak Macar-Kabar boy birliğinin iki dilliliğini zikredebiliriz. Bizans imparatoru buna dair şunu yazmıştır: Kabarlar "bu Türklere Hazarların dilini de öğrettiler ve bu dili bugüne kadar kullandılar, fakat Türklerin diğer dilini de bilirler ${ }^{19}$." Hazar dili, Macar boylarının arasında az çok birbirini takip eden iki dalgada yayılmış olmalıydı. Hazarlarla olan birliktelik ve birlik mücadelesi ilk aşamada yer alırken, Hazar Kağanlığı'ndan ayrılan Kabarlar vasıtası ise ikinci aşamada yer alır. Hazar dilini, her iki aşamada da ilk olarak Macar boy birliğinin yönetici tabakasının bilip kullanmış olması mümkündür ${ }^{20}$.

950 civarına ait Bizans malumatlarından sonra Kabar adı bir daha görülmüyor. 11. yüzyılın başında kaynaklarda Kara Macar (Nigri Ungri) adlandırmasına rastlanır. $\mathrm{Bu}$ adlandırmanın içerisinde

${ }^{15}$ DAI, s. 170 - 171; yine bkz. Tóth, 1984, s. 107.

${ }^{16}$ Németh, 1930,s. 249 - 250, 253; Tóth, 1984, s. 107.

${ }^{17}$ DAI, s. 168 - 168; Németh, 1930, s. 29.

${ }^{18}$ Literatürde Kabarları sekizinci boy olarak gösteren $7+1$ formülü yaygındır, krş. Székely Gy., "Törzsek alkonya - népek születése (Közép- és Kelet-Európa a magyar honfoglalás után)”, Századok, 1976, s. 415 - 416; 7+3’lü kurulan boy birliği için bkz. Tóth, 1984, s. 112.

${ }^{19}$ DAI, s. 174 - 175; Moravcsik, 1984, s. 46.

${ }^{20}$ Makk Ferenc sayesinde bu ihtimal dikkatimi çekti; iki dillilik için genel olarak bkz. Commentary, 150. 
Kabarların haleflerinin aranıp aranmayacağı ya da bu özdeşleştirmenin yapılıp yapılmayacağı Macar tarih biliminin önemli bir sorusudur.

11. yüzy1lda Ademarus Cabannensis, eserinin iki yerinde de Kara Macarları zikreder. Birinci pasaja göre piskopos Bruno, Ausburg şehrinden "Kara Macaristan denilen diğer yerin halkı Etiyopyalılar gibi koyu renkli olduğundan onlardan ayırmak için Ak Macaristan dedikleri Macaristan vilayetine gitti." ${ }^{21}$ Çağdaş bir vakanüvis başka bir yerde şunu yazar: "Kara Macaristan'ı savaşla ele geçirmeye çalışan Macaristan kralı István, tüm o bölgeyi cebren olduğu kadar korku ve sevgiyle de gerçek dine döndürmeyi başardı." 22 Dönemin piskoposu olan Querfurtlu Bruno, bu dini 11. yüzyılın ilk on yılında Macaristan'da yaymıştır. 1008 civarında yazdığı eserinde (Vita quinque fratrum Poloniae) bundan şöyle bahseder: "Ve yeni aziz Adalbert'in katledilmesi nedeniyle daha haklı bir gerekçeyle yöneldiğim Prusyalıları bırakıp - doğudaki kısımlara ulaşmak için gemiye bindim - çelimsiz kolum ve zayıf omzumla Kara Macarlara İncil'i götürme görevini üstlendim." ${ }^{23}$ Piskopos, II. Henrik’e yazdığ1 bir mektubunda (1009) şunu duyduğunu zikretmiştir: "Nitekim Kara Macarlarla ilgili duyduğum kadarıyla Aziz Péter'in heyeti hiç de yersiz olmayan bir gerekçeyle onlara gelmiş, bizimkiler de din değiştirip Hıristiyan olanları, Tanrı affetsin, büyük bir günah işleyerek, kör etmişş ${ }^{24}$."

Kara Macarlardan bahseden bu malumatlar, şüphesiz birçok açıdan yorumlanabilir. Birinci hipotez Kara Macarları, Macar boy birliği (yedi boy) içindeki coğrafî - siyasî - otorite konusunda gruplaşmış sayar ${ }^{25}$. İkinci varsayım, onları yedi Macar boyunun

${ }^{21}$ Gombos F. A., Catalogus fontium historiae Hungaricae I - III, Budapestini, 1937 - 1938 (sonrakilerde Gombos), I, s. 16, “...abiit in provinciam Ungriam, quae dicitur Alba Ungria, ad differentiam alteri Ungarie Nigre, pro eo quod populus est colore fusco velut Etiopes”.

22 Aynı yer, "Stephanus rex Ungrie bello appetens Ungriam Nigram, tam vi quam timore et amore ad fidem veritatis totam illam terram convertere meruit".

${ }^{23}$ Gombos, III, s. 2569, "Et dimissis Pruzis, quo propter novum sanctum, Adalbertum occisum, iustor me causa duxisset, Nigris Ungris, quo tunc versus in partes orientis navim conscendi, sinistro opere er infirmo humero evangelium portare cepi".

${ }^{24}$ Gombos, I, s. 430, “Audivi enim de Nigris Ungris, ad quos, que nunquam frustra vadit, sancti Petri prima legatio venit, quamvis nostri - quod deus indulgeat - cum peccato mango aliquos cecarent(ur), qui conversi omnes facti sunt Christiani”.

${ }^{25}$ Pauler Gy., A magyar nemzet története az Árpádházi királyok alatt I-II, Bp., 18992, I, s. 395, 88. dipnot; Karácsonyi J., Szent István király élete, Bp., 1904, s. 20; Hóman B., - Szekfü Gy., Magyar Történet I., Bp., 1928 (sonrakilerde 
dışındaki Kabarlar ile özdeşleştirir ${ }^{26}$. Kabar - Kara Macar özdeşliği görüşüne dayanan araştırmacıların bir kısmı, göçebe kavimlerdeki ak - kara renginin soyluluğu ya da tabiiyeti ifade etmek için (ayrıca bölgesel uyum için de) kullanıldığı ile delil gösterirler. Buna göre soyluluğu gösteren ak, yedi Macar boyu ile, askerî açıdan yardımcı kavim statülerine atıfta bulunan kara göstergesi ise Kabarlar ile ilgili olmalıdır ${ }^{27}$. Kabarların ten ve yüz renginin Ademarus'un Kara Macarlara dair yaptığı tasvir ile uyumlu olabileceği de vurgulanır ${ }^{28}$.

Kaynaklar, kara renginin tabiiyeti (ya da bölgesel uyumu) gösterdiği varsayımını desteklemiyor. Kabarların ten rengine ilişkin doğrudan bilgimiz yoktur, fakat Hazar Kağanlığı ile ilgili Arap malumatları kullanılabilir: 10. yüzyılda İstahrî’ye göre, "Hazarlar kara saçlıdırlar ve iki türleri vardır. Birincisine Kara Hazar derler, bunlar tıpk1 Hintliler gibi koyu renklidirler. İkinci türü aktır ve dikkat çekici derecede güzeldir ${ }^{29}$." Ademarus ve İstahrî tasvirlerinin karşılaştırmasına dayanarak Kara Hazarların bir kısmının Macarlara katılmış olabileceği olasılığı göz ardı edilemez. Fakat İstahrî'nin Kara Hazarları ile Ademarus'un Kara Macarları arasında hiçbir türden

Hóman), s. 182 - 183; Váczy P., “Gyula és Ajtony”, Emlékkönyv Szentpétery Imre születésének 60-ik évfordulójára, Bp., 1938, s. 502; Molnár E. - Pamlény E. - Székely Gy. (szerk.), Magyarország története I, Bp., 1964, s. 51; Ifj.Horváth J., Székesfehérvár korai történetének néhány kérdese az írásos források alapján, Székesfehérvár évszázadi 1. Az államalapítás kora, Szerk. Kralovánszky A., Székesfehérvár, 1967 (sonrakilerde Horváth, 1967), s. 107 110; Tóth S., “A fehér és fekete magyarok kérdéséhez”, Acta Universitatis Szediensis de Attila József nominate, Acta Historica (sonrakilerde AUSZ), Tomus LXXV, Szeged, 1983 (sonrakilerde Tóth, 1983), s. 7 - 8; Kristó Gy., Magyarország története 895 - 1301 (Egyetemi jegyzet), Bp., 1984, s. 35.

${ }^{26}$ Györffy Gy., Tanulmányok a magyar állam eredetéröl. A nemzetségtöl a vármegyéig, a törzstöl az országig. Kurszán és Kurszán vára, Bp., 1959 (sonrakilerde Györffy, 1959), s. 76; Györffy Gy., “A honfoglaló magyarok települési rendjéröl”, Archaeologiai Értesítő, 1970, s. 135; Györffy Gy., István király és müve, Bp., 1977 (sonrakilerde Györffy, 1977), s. 166, 173; Györffy Gy., Magyarország története tíz kötetben I/1-2. Elözmények és a magyar történet 1242-ig (Föszerk. Székely Gy.), Bp., 1984, s. 718, 767 - 768; Kristó Gy., “A fekete magyarok és pécsi püspökség alapítása”, AUSZ, Tomus LXXXII, Szeged, 1985 (sonrakilerde Kristó, 1985), s. 15 - 16.

${ }^{27}$ Renk sembollerine ilişkin genel olarak bkz. Horváth, 1967, s. 108 - 110; buna benzer olarak ak-kara Macar farklılığını bölgesel uyumla ilişkilendiren Tóth, 1983, s. 7; bununla bağlantılı literatür için bkz. aynı yerde s. 36 - 37. dipnot; Ak- Kara sembollerinin Macarlar ve Kabarlar ile bağlantısı için bkz. Györffy, 1959, s. $75-76$.

${ }^{28}$ Györffy, 1959, s. 76; Kristó, 1985, s. 15.

${ }^{29}$ Istahrî’nin malumatını Golden aktarmıştır, fakat o daha çok siyasi anlamını vurgular, ona göre Kara Hazar, Hazar halkına, Ak Hazar ise soylulara atıfta bulunuyor olmaliyd. Golden, 1980, s. 103, 142. 
bağlantının olmaması da mümkündür. Kara Macar nitelemesi yalnızca Kabarlara değil, Macarlara da (ya da bir kısmına) gönderme yapıyor olmalıdır. Rus Ana Vakayinamesi'nin yılsız, güvenirliği şüpheli bir kısmında önce Bizans imparatoru Herakleios dönemindeki (610 641) Ak Ugorlardan bilgi verir, sonra şunu zikreder : "Peçenekler geldiler, Ak Ugorlar daha sonra Oleg zamanında Kiev yakınlarına gittiler $^{30} \ldots$ ” Knez Oleg döneminde (879 - 912) rol oynayan Peçeneklerin Güney Rus bozkırında ortaya çıkışları sırasında Kiev yakınlarına ilerleyen Ak Ugorlarda, Kabarlardan ziyade Macarları görebiliriz ${ }^{31}$. Konstantinos'a göre Macarların eski adı Savartoi Asfaloi idi, 950 civarında bu adlandırmayı Kafkasya sahasına yürüyen ve Etelköz'deki Macarlardan ayrılan grup da kullanmıştı. Bizans imparatoru diğer eserinde (De Cerimoniis), Savard adının "kara oğlanlar" anlamına geldiğini iddia $\operatorname{eder}^{32}$. Aynı zamanda Macaristan'da uzun süre vakit geçiren Querfurtlu Bruno da Macarlar (Ungri) ve Kara Macarlar (Nigri Ungri) göstergesini kullanmıştır; onun için bunlar muhtemelen din değiştiren aynı nüfusu ifade ediyordu. Simon Kézai ve büyük olasılıkla XIV. yüzyılda yazılmış bir kroniğe ait iddiaya göre, İskitya halkının rengi “...aktan çok $\operatorname{karadır}^{33}$." Macar vakanüvislerinin geleneği, İskitya'yı Macarların yeni yurtlarına göç etmeden önceki anayurdu olarak gördüğü için, ten rengi ile bağlantılı bu tespit, Macarlara da bağlanabilir. 14. yüzyılın başında yazılan Descriptio Europae Orientalis adlı çalışmanın isimsiz yazarına göre Macarların rengi karadır ${ }^{34}$.

\footnotetext{
${ }^{30}$ Hodinka A., Az orosz évkönyvek magyar vonatkozásai, Bp., 1916, s. 34 - 35; A magyarok elödeiröl és a honfoglalásról, Szerk. Györffy Gy., Bp., 1975² (sonrakilerde MEH), s. 126.

${ }^{31}$ Daha önce PVL'nin Ak Ugorlarını da Macarlar ile ilişskilendirmiştik (krş. Tóth, 1983, s. 4); Györffy, Ak Ugorları yedi Macar boyu ile, Kara Ugorları ise Kabarlar ile özdeşleştirmiş̧ir, Györffy, 1959, s. 76, 246. dipnot; MEH, 11, s. 284, 247. ve 250. dipnot; Bartha A., A IX - X. sázadi magyar társadalom, 1968, s. 82 - 83; en yeni tespite göre (Bartha A.) Ak Macarlardan Hazarlar anlaşılmalıdır, bkz. Magyarország története, I/1, s. 552.

${ }^{32}$ DAI, s. 170 - 171; De Cerimoniis, Hrsg. von Reiske, J. J., Bonn, 1829, 687; yine bkz. Pritsak, O., "Orientierung und Farbsymbolik", Saeculum 4 (1953), s. 378.

${ }^{33}$ Emericus Szentpétery, Scriptores rerum Hungaricum ducum regumque stirpis Arpadiane gestarum, I - II, Budapestini, 1937 - 1938 (sonrakilerde SRH), I, s. 145, 252.

${ }^{34}$ Anonymi Descriptio Europae Orientalis, Imperium Constantinopolitanum, Albania, Serbia, Bulgaria, Ruthena, Ungaria, Polonia, Bohemia anno MCCCVIII, exarata, ed. Górka, O., Cracoviae, 1916, s. 49; Macarcaya çeviren Borzákné Nacsa M., A Descriptio Europae Orientalis eszmei háttére és politikai célzatossága (Doktora Tezi), Kecskemét, 1985.
} 
Yukarıdakilere dayanarak kara göstergesini onlara katılan Hazarlara olduğu gibi, keza haklı olarak Macar boylarına da bağlayabiliriz. Bu yüzden 11. yüzyılın başında kimlerin Kara Macarlar olarak adlandırıldığını tespit edebilmemiz için aşağıdaki incelemeyi yapmamiz gerekiyor. Ademarus Cabannensis ve Querfurtlu Bruno'nun malumatlarından ten rengi dışında aşağıdaki iki önemli gerçek ortaya çıkar:

1. István, Kara Macarlara karşı savaş başlattı.

2. Kara Macarlar pagan idiler, onların arasında misyonerlik yapıldı ve güç kullanılarak yapılan misyonerlik faaliyetleri, nihayetinde başarıyla sonuçlandı.

István'ın Koppány (997), Gyula (1003) ve Ajtony’ye (1020’li yıllar) karşı mücadele ettiğini diğer kaynaklara istinaden biliyoruz. Géza'nın ölümünden sonra onun dul eşi ve prenslik unvanı için aday olan Koppány, István'ın baba kolundan, Gyula ise anne kolundan akrabası idi ${ }^{35}$. Akrabalık bağlarına rağmen hem Koppány, hem de Gyula, István'ın düşmanı idi. Aynı şey kral ile ailevî bir bağı olmayan Ajtony için de söylenebilir ${ }^{36}$. Bunların şahsiyetlerinde, boy birliğini yavaş yavaş sona erdiren ve birleşik bir krallık kurmaya çalışan István'a karşı boyculuk ve siyasal farklılaşma eğilimleri vücut buldu. Her ne kadar Ajtony vaftiz edilse de ve kroniğin iddiasına rağmen Gyula'nın da vaftiz edilme ihtimalini göz ardı etmesek de, I. István'a isyan eden bir lideri gerçekten de Hıristiyan olarak sayamıyoruz: bölgelerinin nüfusu ise herhalde genel olarak pagan olmalıydı ${ }^{37}$. Géza'nın başlatıp István'ın sürdürdüğü saldırı, yönünü büyük prenslik (sonra krallık) gücünün yayılmasına ve onunla bağlantılı olarak Hıristiyanlığın genele yayılmasına çevirdi. Bazı boylar hükümdara ve Hıristiyanlığa karşı meşru bir şsekilde muhalefet etmişlerdi; 11. yüzyılın başına ait kaynaklarda geçen Kara Macar göstergesi bunlarla ilgilidir. Querfurtlu Bruno, Hiristiyanlığı muhtemelen

\footnotetext{
${ }^{35}$ Koppány’ye karşı savaş için bkz. SRH, I., s. 296, 297, 312-314; daha fazlası için yine bkz. Györffy, 1977, s. 110 - 121; Kristó Gy., Tanulmányok az Árpádkorról, Bp., 1983 (sonrakilerde Kristó, 1983), s. 16 - 17, 77 - 92; Gyula'ya karş1 savaş için bkz. SRH, I, s. 172, 314 - 315; Gombos, I, s. 92, 141; yine bkz. Györffy, 1977, s. $169-171$.

${ }^{36}$ Ajtony için bkz. SRH, I, s. 50, 89 - 90, II, s. 489 - 492, 505; yine bkz. Kristó Gy., "Megjegyzesék az ún. Pogánylázadások kora történetéhez", AUSZ, Tomus XVIII, Szeged, 1965 (sonrakilerde Kristó, 1965), s. 7 - 19; Györffy, 1977, s. $171-176$.

${ }^{37}$ Koppány’yi takip edenlerin paganlı̆̆ı için bkz. SRH, I, s. 297; Gyula'nın inançsızlı̆̆ değildi. bkz. SRH, II, s. 489.
} 
1009 'da kurduğu Peşte Piskoposluğu'nun topraklarında yaşayan Kara Macarlar arasında yaymıştı ${ }^{38}$. Bu bölge önceden belki de Koppány’nin yönetimi altındaydı; ya da belki de burada ondan bağımsız bir boy yaşıyordu $^{39}$. Kara Macarlara karşı István'ın başlattığı sefer, Erdel'deki Gyula'ya karşı yapılan savaşa bağlanabildiği gibi, aynı şekilde Güney Tuna ötesi bölgesinin fethine de bağlanabilir ${ }^{40}$. Maros ve Aşağı Tuna arasında hüküm süren Ajtony'nin halkını, kronolojik sebeplerden dolayı 11. yüzyıl başına ait kaynakların Kara Macarları arasından çıkartabiliriz; çünkü bu bölgede Csanád Piskoposluğu ancak 1030'da kurulmuştu, bu yüzden Querfurtlu Bruno'nun din değiştirttiği Kara Macarlar, Ajtony'nin bölgesinde yaşamış olamazlar ${ }^{41}$. Keza, yukarıdakilere dayanarak Koppány ve Gyula'nın halkını Kara Macarlardan sayabiliriz. Literatürde genel olarak kabul edilmiş ve yaygınlık kazanmış görüşe göre, 11. yüzyılda Kabar boyunun beyi Aba Sámuel idi' ${ }^{42}$, bu yüzden Kabarlarl Kara Macarlar olarak adlandıramıyoruz. Bir yandan Aba Sámuel, István'ın en küçük kız kardeşinin kocası olarak kayın biraderi ile müttefik idi, ${ }^{43}$ bu yüzden István'a karşı neredeyse hiç sefere çıkmamıştır. Öte yandan Aba ulusunun yurdu Mátra bölgesinde idi, bu nedenle bir blok halinde bulunan Kabar boyuna ait yurt da 11. yüzyılın ilk on yılında Kara Macarların yaşadığı Güney Tuna ötesinde ya da Erdel'de değil, muhtemelen Karpat Havzası'nın kuzey ve kuzeydoğu kısmında olmaliyd $1^{44}$.

Kara Macar adlandırması uzun ömürlü olmadı, büyük olasılıkla devletin kuruluşundan ve Aziz István'ın hükümdarlığından sonra da yaşamadı. Şayet 950'den sonra iz bırakmaksızın kaynaklardan kaybolan Kabarların, geç halefleri olarak Kalizler ya da Sekeller görülüyorsa, bunu bir sonuca bağlamak sonraki araştırmaların vazifesidir.

\footnotetext{
${ }^{38}$ Kristó, 1985, s. $11-16$.

${ }^{39}$ Aynı yer, s. 15 - 16. Ona göre Kabarların yaşadığı ilk yer burada idi.

${ }^{40}$ Bkz. 36. dipnot; Erdel’deki Gyula için bkz. Horváth, 1967, s. 107.

${ }^{41}$ Csanád Piskoposluğu'nun kuruluş zamanı için bkz. SRH, I, s. 125; Györffy, Ajtony üzerine yapılan seferi 1008'e koyar. Györffy, 1977, s. 172 - 173; 1020'li y1llara koyan Kristó, 1965, s. $17-18$.

${ }^{42}$ Aba'nın kökeni için bkz. SRH, I, s. 73, 163, 278, 280; Kabar oluşuna dair bkz. Hóman, 1928, s. 67 - 68; Kristó, 1983, s. 454 - 457; Györffy, Magyarország története $\mathrm{I} / 1$, s. 839.

43 Hóman, 1928, s. 203 - 204; Vajay Sz., Géza nagyfejedelem és családja. Székesfehérvár évszázadai 1. Székesfehérvár, 1967, s. 70 - 71, 99 - 100; Kristó, 1983, s. 89 - 91; Györffy’ye göre (Magyarország története I/1, s. 839) Aba'nın babası olan Csaba, kralın eniştesinin (sororius) naibi idi.

${ }^{44}$ Hóman, 1928, s. 123; Kristó, 1980, s. 455 - 457.
} 